\title{
PELATIHAN PEMASANGAN LAMPU LISTRIK BERSAKLAR DI RUMAH TANGGA MENGGUNAKAN KONSEP EWB (ELECTRONICS WORKBENCH) BAGI SISWA SMKN I BATU KLIANG UTARA DESA AIK BERIQ KECAMATAN BATU KLIANG UTARA KABUPATEN LOMBOK TENGAH TAHUN 2017
}

\author{
Islahudin $^{1^{*}}$, Johri Sabaryati ${ }^{2}$ \\ ${ }^{\star}$ Program Studi Pendidikan Fisika, Fakultas Keguruan dan IImu Pendidikan, Universitas Muhammadiyah Mataram \\ 2 Program Studi Pendidikan Fisika, Fakultas Keguruan dan IImu Pendidikan, Universitas Muhammadiyah Mataram \\ ${ }^{*}$ Corresponding author : \\ E-mail : islahudin.ntb@gmail.com
}

Diterima 10 April 2018, Disetujui 13 April 2018

\begin{abstract}
ABSTRAK
Pengetahuan tentang listrik merupakan salah satu sarana untuk mengerti tentang perkembangan teknologi yang terjadi saat ini. Oleh karena itu, peranan guru dalam mengajarkan siswa tentang rangkaian listrik sangat penting. Guru terutama guru sains fisika harus mampu mengerti tentang rangkaian listrik baik secara teoritis maupun praktik. Salah satu cara agar guru dan siswa mengerti dan menguasai tentang rangkaian listrik adalah dengan mengadakan pelatihan pemasangan lampu listrik di rumah tangga menggunakan media EWB (Electronics Workbench) sehingga dapat digunakan dalam memahami rangkaian listrik di dalam rumah tangga. Tujuan diadakan kegiatan pelatihan ini adalah untuk memberikan pelatihan pemasangan lampu bersaklar listrik menggunakan media EWB yang dapat membantu siswa maupun guru dalam membuat rangkaian listrik dan untuk meningkatkan kemampuan guru dan siswa dalam mengikuti perkembangan software simulasi yang ada saat ini. Pengabdian masyarakat ini dilaksanakan di SMKN 1 Batu Kliang Utara Desa Aiq Beriq, Kecamatan Batu Kliang Utara, Kabupaten Lombok Tengah. Kegiatan ini diikuti oleh 19 orang peserta yang merupakan siswa/i SMKN 1 Batu Kliang Utara Desa Aiq Beriq. Kegiatan pelatihan ini berlangsung selama dua hari dan berjalan dengan lancar tanpa ada hambatan dengan antusiasme peserta untuk mengikuti pelatihan ini yang sangat besar terlihat dari kehadiran yang lengkap mulai dari acara pembukaan sampai penutupan pelatihan.
\end{abstract}

Kata Kunci: Pelatihan, Pemasangan Lampu Listrik Rumah Tangga, Media EWB.

\begin{abstract}
Knowledge of electricity is one means to understand the current technological developments. Hence, the role of teachers in teaching their students about the electrical circuit is very substantial. Teachers, especially physics science teachers, should be able to understand the electrical circuit both theoretically and practically. One of the means both teachers and students to understand and master the electrical circuit is provide the training on installation of household electric lights using EWB (Electronics Workbench) media so that it can be used in understanding the electrical circuit in the household. The objectives of this training were to provide the training on the installation of Household Electric Lights using EWB media that can help students and teachers in making electrical circuits and to improve the ability of teachers and students in following the current simulation software development. This training held in SMKN 1 Batu Kliang Utara Aiq Beriq Village, Batu Kliang Utara Sub-District, Central Lombok Regency and was followed by 19 participants who were students of SMKN 1 Batu Kliang Utara Aiq Beriq Village. This training held two days and went well without any obstacles with the great enthusiasm of participants to attend the training from the opening to the closing.
\end{abstract}

Keywords: Training, Installation of Household Electric Lights, EWB Media.

\section{PENDAHULUAN}

Desa Aiq Beriq, Kecamatan Batukliang

Utara merupakan wilayah yang subur serta memiliki geografis yang merupakan daerah persawahan. Kondisi perumahan warga di daerah 
tersebut juga masih belum terkonsentrasi secara merata sebagaimana yang terdapat di desa yang lain. Berdasarkan keadaan alamnya yang masih sebagian besar lahan persawahan, bidang pertanian merupakan sumber pencaharian terbesar khususnya tanaman padi.

Selain memiliki wilayah persawahan yang cukup luas, perkembangan pendidikan di Desa Aik berik juga sangat tinggi. Hal ini terlihat dengan adanya tingkat satuan pendidikan yang cukup lengkap, terutama sekolah SMP/Mts dan SMA/MA/SMK baik negeri maupun swasta. Beberapa sekolah di daerah tersebut khususnya SMP dan SMA negeri sudah memiliki sarana dan prasarana pendidikan yang cukup memadai seperti perpustakaan dan laboratorium. Namun sebagian besar sekolah yang lain masih menggunakan sarana dan prasarana belajar yang masih apa adanya.

Sumber belajar seperti buku paket dan LKS sudah sangat banyak dimanfaatkan oleh siswa-siswi di masing-masing sekolah. Beberapa sekolah juga sudah memanfaatkan media ICT sebagai sumber belajar terutama internet. Perkembangan zaman yang sangat pesat saat ini membuat pihak sekolah mengharuskan peserta didiknya untuk selalu menggunakan sumber belajar baik berupa buku paket maupun teknologi informatika tersebut secara tekun dan rajin agar menambah wawasan pengetahuan lebih luas lagi.

Selain sumber belajar berupa buku dan ICT, sumber belajar yang juga sangat penting adalah laboratorium. Laboratorium merupakan tempat bagi siswa untuk melakukan beberapa percobaan ilmiah. Laboratorium sangat dibutuhkan oleh setiap sekolah, terutama sekolah yang memiliki jurusan IPA pada Sekolah Menengah Atas atau Madrasah Aliyah. Laboratorium yang paling sering digunakan pada jurusan IPA antara lain, laboratorium fisika, biologi, kimia, dan matematika. Belajar sambil bereksperimen di laboratorium sangat membantu siswa dalam memahami gejala alam di sekitar kita. Selain bisa mengetahui adanya keteraturan alam yang sudah diciptakan oleh Sang Pencipta, belajar di laboratorium juga memberikan kesan belajar yang sangat berbeda dibandingkan belajar dengan hanya menggunakan buku paket atau teori. Khusus di Desa Aik Berik, sekolah menengah atas yang memiliki sarana penunjang laboratorium baik laboratorium komputer dan laboratorium IPA yang cukup lengkap adalah SMKN 1 Batukliang Utara. Sekolah ini memiliki beberapa jurusan antara lain jurusan energi terbarukan, jurusan multimedia, jurusan pariwisata dan jurusan komputer.

Salah satu pengetahuan IPA yang harus dimiliki oleh siswa adalah kemampuan merangkai rangkaian listrik dalam rumah tangga/rumah tinggal. Pemakaian alat-alat listrik dalam kehidupan sehari-hari saat ini terutama dalam rumah tangga sudah sangat banyak. Sejak usia dini masyarakat dalam hal ini karang tarunadan siswa sangat perlu untuk banyak belajar rangkaian dan pengukuran listrik dalam rumah mereka. Pengetahuan tentang listrik merupakan salah satu sarana untuk mengerti tentang perkembangan teknologi yang terjadi saat ini. Oleh karena itu, peranan guru dalam mengajarkan siswa tentang rangkaian listrik sangat besar. Guru terutama guru sains fisika harus mampu mengerti tentang rangkaian listrik baik secara teoritis maupun praktik. Salah satu cara agar masyarakat, guru, dan siswa mengerti dan menguasai tentang rangkaian listrik rumah tinggal adalah menggunakan media EWB (Electronics Workbench). Media EWB (Electronics Workbench) sangat cocok untuk dijadikan media belajar pemasangan lampu listrik di rumah tangga sehingga nantinya siswa sebagai remaja di Desa Mas-Mas dapat memasang sendiri atau minimal dapat memperbaiki rangkaian listrik di rumahnya tanpa harus memanggil tukang listrik yang tentunya akan mengeluarkan banyak waktu dan biaya. Berdasarkan hal yang sudah dipaparkan tersebut maka pengusul mengangkat topik pengabdian pada masyarakat dengan judul " Pelatihan Pemasangan Rangkaian Listrik Rumah Tangga Menggunakan Konsep EWB (ELECTRONICS WORKBENCH) Bagi Siswa SMKN I Batu Kliang Utara Desa Aiq Beriq Kecamatan Batukliang Utara Kabupaten Lombok Tengah Tahun 2017".

\section{HASIL DAN PEMBAHASAN}

Software EWB (Electronics Workbench) merupakan software dari Interactive Image Technology Ltd. Electronics Workbench adalah sebuah software untuk elektronika. Dalam Electronics Workbench terdapat beberapa tools yang bisa di aplikasikan dalam membuat rangkaian listrik sistem digital. Softwrars FIN/B dilengkapi simulator yang standar dal 1 si software yang tinggi terdiri dari schemaulc euıtor, simulator SPICE dan on-screen wave forms membuat Electronics Workbench begitu mudah digunakan.

Simulasi tools yang ditawarkan oleh EWB memberikan kemudahan baik bagi siswa dan guru sehingga tidak perlu menghabiskan banyak dana dan waktu untuk membeli IC atau komponen yang lain yang diperlukan, cukup duduk manis di depan komputer. Tidak perlu menyolder sehingga waktu tidak terbuang sia-sia. Tidak perlu membeli instrumen pengukuran 
karena semuanya sudah tersedia dalam simulasi. Selain itu, siswa bahkan guru bisa belajar merangkai rangkaian listrik dimanapun dan kapanpun, karena sudah tidak lagi dibatasi oleh kurangnya kit listrik maupun ruangan laboratorium. Namun hal tersebut tidak serta merta membuat siswa dan guru untuk malas mengerjakan suatu projek elektronika atau rangkaian listrik di laboratorium. Karena praktek secara langsung akan memiliki rasa yang berbeda dibanding hanya sekedar simulasi. Dengan demikian dapat disimpulkan bahwa EWB merupakan software yang bisa digunakan untuk mengatasi masalah kekurangan alat listrik di laboratorium sehingga dapat digunakan baik oleh siswa maupun siswa.

Pelatihan pemasangan lampu listrik di rumah tangga menggunakan media EWB (Electronics Workbench) ini di laksanakan dengan metode praktikum. Peralatan yang digunakan antara lain saklar listrik sebanyak 5 set dan 1 buah LCD proyektor. Adapun peserta pelatihan sebanyak 20 orang. Masing-masing peserta mengikuti pelatihan berdasarkan modul pelatihan yang sudah dibagikan. Materi pelatihan yang diajarkan adalah merangkai rangkaian listrik seri, rangkaian listrik paralel, dan rangkaian listrik kombinasi antara seri dan paralel. Adapun tahapan pelatihan ini antara lain: 1).Penyusunan modul dan jadwal pelatihan, 2).Menginstal software EWB pada masing-masing laptop pesert, 3).Menjelaskan pengertian dari EWB, 4).Mempraktikkan cara merangkai rangkaian listrik seri dengan EWB, 5).Mempraktikkan secara rinci cara mengukur tegangan dan arus listrik pada rangkaian seri menggunakan multimeter pada menu EWB, 6).Mempraktikkan cara merangkai rangkaian listrik paralel dengan EWB, 7).Mempraktikkan secara rinci cara mengukur tegangan dan arus listrik pada rangkaian paralel menggunakan multimeter pada menu EWB, 8).Mempraktikkan cara merangkai rangkaian kombinasi listrik seri dan paralel dengan EWB, 9).Mempraktikkan secara rinci cara memasang saklar listrik pada rangkaian kombinasi listrik seri dan parallel, 10).Memberikan kesempatan kepada para peserta pelatihan untuk melakukan pelatihan sesuai dengan modul yang sudah diberikan, 11).Membagi peserta menjadi 3 kelompok dengan perkelompok terdiri dari orang, 12).Memberikan kesempatan kepada para peserta untuk membuat rangkaian seri, rangkaian paralel, dan kombinasi seri-paralel menggunakan EWB, 13).Membimbing para peserta yang belum mengerti tentang bagaimana merangkai komponen listrik pada EWB, 14).Membimbing para peserta memasang saklar listrik pada rangkaian listrik seri dan parallel, 15).Memeriksa hasil kerja peserta masing-masing peserta dan memberikan kesempatan kepada kelompok yang sudah menyelesaikan rangkaian EWB dan pemsangan saklar untuk mempresentasikan hasil kerja kelompoknya di depan para peserta yang lainnya, 16).Mengoreksi hasil kerja peserta jika terdapat kesalahan.

Pelatihan EWB ini efektif terlaksana selama 1 hari penuh yakni hari Senin, 13 November 2017, yang sebelumnya direncanakan untuk dilakukan selama 2 hari (Senin dan selasa tanggal 13 dan 14 November 2017). Hal ini terjadi karena pada hari pertama pelatihan, peserta diberikan sosialisasi dan pelatihan tentang kit listrik dengan menggunakan fasilitas EWB kemudian memberikan kesempatan kepada masing-masing kelompok secara mandiri pada hari berikutnya (hari ke-2) untuk mempresentasikan pemasangan saklar listrik yang sudah mereka buat.

Pelatihan Pemasangan Lampu Listrik Bersaklar di Rumah Tangga Menggunakan Konsep EWB (Electronics Workbench) Bagi Siswa SMKN 1 Batu Kliang Utara ini berjalan dengan lancar tanpa hambatan yang cukup berarti. Antusiasme peserta untuk mengikuti pelatihan ini sangat besar. Hal ini terlihat dengan para peserta yang lengkap kehadirannya mulai dari acara pembukaan sampai penutupan pelatihan. Namun ada beberapa masalah yang ditemukan selama proses pelatihan ini, antara lain: 1).Mitra/peserta belum mahir menyusun rangkaian pada papan rangkaian sehingga harus tetap didampingi oleh mahasiswa Program Studi Pendidikan Fisika UM Mataram, 2).Peserta yang ikut dalam pelatihan ini sebagian besar belum mengenal EWB dengan baik. Akibatnya kegiatan pelatihan sebagian terfokus pada topik yang berada modul pelatihan, 3).Peserta pelatihan belum familiar menggunakan program EWB karena software ini merupakan software baru baik bagi guru maupun bagi siswa, 4).Peserta yang ikut dalam pelatihan ini sebagian besar mengalami kesulitan dalam memasang saklar lampu listrik, karena mereka sangat jarang memegang alat-alat listrik sehingga proses pelatihan membutuhkan penjelasan yang detail.

\section{SIMPULAN DAN SARAN Simpulan}

Berdasarkan pelatihan pemasangan lampu listrik bersaklar di rumah tangga menggunakan konsep EWB (Electronics Workbench) yang telah dilakukan maka kesimpulan yang diperoleh antara lain:

1. Pelatihan membuat rangkaian listrik seri dan paralel menggunakan software EWB ini sangat cocok sebagai sarana untuk mengerti tentang 
kelistrikan untuk siswa SMKN 1 Batu Kliang Utara. Hal ini karena membuat kit listrik menggunakan EWB tidak memerlukan komponen-komponen listrik yang mahal.

2. Pelatihan Pemasangan Lampu Listrik Bersaklar di Rumah Tangga Menggunakan Konsep EWB (Electronics Workbench) sangat membantu peserta dalam memahami aplikasi kelistrikan pada instalasi listrik di dalam rumah tangga.

3. Pelaksanaan pelatihan secara teknis berjalan cukup lancar tanpa ada hambatan yang cukup berarti. Namun ada beberapa permasalahan yang timbul walaupun tidak begitu besar yakni masih ada peserta yang masung kurangnya kemampuan dalam menjalankan program komputer dan software EWB.

\section{Saran}

Adapun saran yang dapat dikemukakan berdasarkan pelatihan ini antara lain:

1. Perlu ada pelatihan secara berkelanjutan agar program EWB bisa dipahami secara mendalam.

2. Pemasangan lampu listrik bersaklar di rumah tangga menggunakan konsep EWB (Electronics Workbench) perlu diaplikasikan secara langsung oleh para peserta terutama sekali ketika peserta ingin memperbaiki sendiri instalasi listrik di dalam rumahnya.

\section{DAFTAR RUJUKAN}

Islahudin, I., Darmayanti, N.W.S., Zulkarnain, Z, (2017). Pengaruh Pemanfaatan Alat Peraga Berbasis Kearifan Lokal Terhadap Peningkatan Hasil Belajar Fisika Pada Siswa Kelas VIII DI MTs Nurul Iman NW Kembang Kerang Lombok Tengah Tahun Pelajaran 2017/2018. ORBITA : Jurnal Kajian, Inovasi, dan Aplikasi Pendidikan Fisika, 3(2), 69-74

Islahudin, I., Isnaini, M, (2019). Pemanfaatan Laboratorium Virtual Berbasis Software Electronics Workbench (EWB) Untuk Menunjang Pemahaman Konsep Mahasiswa Pada Mata Kuliah Elektronika Dasar I, ORBITA : Jurnal Kajian, Inovasi, dan Aplikasi Pendidikan Fisika, 5(2), 96100

Islahudin, I., Khaerani, Siti., Zulkarnain, Z, (2018). Pemanfaatan Laboratorium Virtual Berbasis EWB (Electronics Workbench) Terhadap Peningkatan Hasil Belajar Fisika Siswa IPA Kelas XII IPA MA NW Darussalimin Sengkol, Batukliang Lombok Tengah Tahun Pelajaran 2018/2019, ORBITA :
Jurnal Kajian, Inovasi, dan Aplikasi Pendidikan Fisika, 4(2), 47-51

Luh Putu Budi Yasmini, dkk. 2014. Pelatihan Penggunaan IC 555 untuk Meningkatkan Keterampilan Guru Fisika SMP dan SMA Pembinaan Ekstrakuliker Elektronik Di Kecamatan Buleleng. Seminar Nasional FMIPA UNDIKSHA IV Tahun 2014.

Nurkancana, dkk. 1991. Evaluasi Hasil Belajar. Surabaya: Usaha Nasional. . 1983. Evaluasi Hasil Belajar. Surabaya: Usaha Nasional.

Suraya, Ayu. 2014. Pengaruh Penggunaan Media Pembelajaran Software Electronics Workbench (EWB) Terhadap Hasil Belajar Siswa Pada Kompetensi Dasar Menerapkan Macam-Macam Rangkaian Flip-Flop Kelas X TAV Di SMK Negeri 1 Madiun. Jurnal Pendidikan Teknik Elektro. Volume 03 Nomor 02, Tahun 2014, 289294

Sugiono 2010. Metode Penelitian Kuantitatif Kualitatif dan R \& d. Bandung: CV Alfabeta. 2008. Metode Penelitian Kuantitatif Kualitatif dan R \& d. Bandung: CV Alfabeta.

Winarno. 2012. Pembuatan Media Pembelajaran Interaktif Elektronika Dasar Pada Sekolah Menengah Kejuruan Teknik Elektronika Audio Video. Journal Speed - Sentra Penelitian Engineering dan Edukasi Volume 4 No 3 - 2012 - ijns.org 